\title{
Bill disparity and feeding strategies among fossil and modern penguins
}

\author{
Martín Chávez-Hoffmeister (D)
}

\begin{abstract}
One of the most remarkable differences between Paleogene penguins and their living relatives is the shape and length of their beaks. Many of the Eocene and Oligocene penguins have a thin and elongated spear-like bill, which contrasts with the proportionally shorter and more robust bill of most living species. These differences suggest an important shift in their feeding strategies. This study explores the morphological disparity on the skull of penguins, emphasizing bill morphology and it relationship with feeding habits. For this, the skulls of 118 species of aquatic birds, including 21 fossil and living penguins, were analyzed using two-dimensional geometric morphometric. The results show that, unlike what has been reported for modern birds overall, in penguins and Aequornithes, bill elongation is related to a reduction of the braincase. The discriminant analysis shows that there are significant differences between penguins that feed near or far from the coast and between those that consume nectonic and planktonic prey, identifying Madrynornis as the only extinct form with a possibly planktonic diet. Additionally, it is clear that Paleogene penguins occupy a region of morphospace unexplored by most diving birds, with the western grebe being their closest modern analogue. This is consistent with the hypothesis that giant penguins hunted by harpooning and not by biting as living forms do, signaling a significant change in the habits of those birds leading to the emergence of their crown group.
\end{abstract}

Martín Chávez-Hoffmeister. Laboratorio de Paleontología, Instituto de Ciencias de la Tierra, Universidad Austral de Chile, Valdivia, Chile. E-mail: paleoaeolos@gmail.com

Accepted: 28 January 2020

Data available from the Dryad Digital Repository: https://doi.org/10.5061/dryad.08kprr4zf

\section{Introduction}

Though very little was known about the cranial morphology of stem penguins until the twenty-first century, we know now that one of the most striking differences between extant penguins and their Paleogene relatives can be seen in their bills (Fig. 1). Many stem penguins shared a distinctive and extremely elongated spear-like bill (Ksepka and Ando 2011), representing more than two-thirds of the skull length. This contrast with the shorter and more robust beak present on most modern penguins suggests an important shift in their feeding strategies. Some of the first indications of this extreme morphology on Paleogene penguins were mentioned by Marples (1952), who pointed out the existence of associated skull fragments for the partial skeleton OM GL427 currently assigned to Kairuku (Ksepka et al. 2012) and for the holotype of Archaeospheniscus lowei. The first included a partial beak described as straight and overall similar to the long beak of the modern king penguin, whereas the second is a straight and pointed fragment of jaw with an unusually long symphysis. In fact, the latter specimen was so different from any modern taxa that Marples was not even sure whether it belonged to a penguin. Later, Olson (1985) and Myrcha et al. (1990) presented the first well-preserved beaks from La Meseta, tentatively referred to as the "giant" penguins Palaeeudyptes or Anthropornis, revealing for the first time the existence of a long spear-like beak in the Eocene taxa. The subsequent discovery of Waimanu (Slack et al. 2006), Icadyptes (Clarke et al. 2007), and Inkayacu (Clarke et al. 2010) showed that a narrow and slender pointed bill was indeed common among Paleogene taxa, and this is now considered as a character shared by most of the stem penguins (Ksepka and Ando 2011).

In contrast, modern penguins tend to have shorter and bulkier bills. The great penguins (Aptenodytes) are the only exception among 


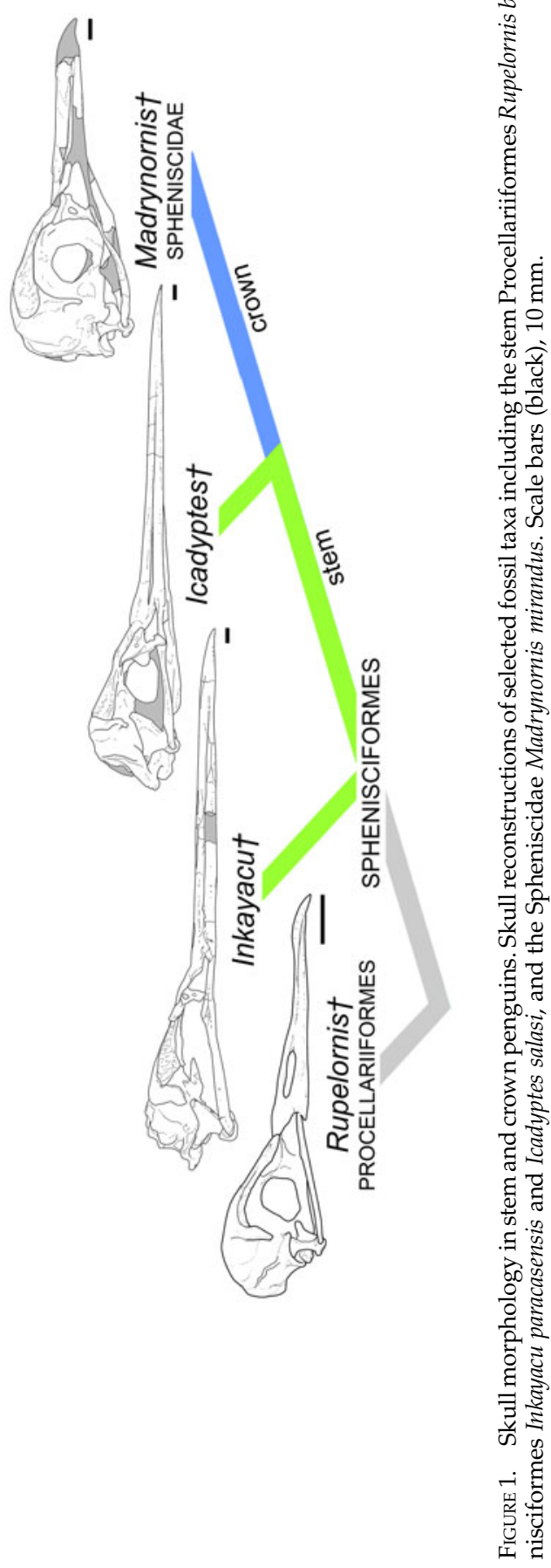

extant taxa, possessing long and slender bills resembling the condition observed in more primitive forms, but being proportionally shorter. Short bills are also known in some fossil taxa, all of which have been identified as closely related or members of the crown group (Ksepka and Clarke 2010). Both Madrynornis and Palaeospheniscus had short beaks similar to those of most extant penguins (Acosta Hospitaleche et al. 2007, 2008), whereas Spheniscus urbinai and Spheniscus megaramphus are distinctive in having larger and overall bulkier bills than their living relatives (Stucchi 2002; Stucchi et al. 2003).

These differences between stem and crown taxa points to an important shift in feeding strategies during the evolution of penguins. Zusi (1975) noticed that the morphology of both upper and lower jaws is particularly distinctive between living penguins specialized for preying on small shoaling organisms (i.e., krill) versus those specialized on fish. Krilleating penguins have wider beaks and broader jaws with reduced symphyses to accommodate an enlarged tongue, whereas fish eaters have narrower but more robust beaks and longer postarticular processes in their jaws to allow more mobility and support increased bite forces. Considering that such differences are subtle compared with the remarkable disparity observed between stem and crown taxa, it is safe to assume that those modifications are most likely related to changes in feeding strategies. It has been suggested that the spear-like beak of stem penguins is suitable for spearing large prey (Olson 1985; Myrcha et al. 1990), whereas the capture of smaller shoaling prey seems to have been a strategy that evolved close to or within the crown group (Ksepka and Bertelli 2006), although others have suggested that plankton eaters could have already appeared by the late Eocene (Haidr and Acosta Hospitaleche 2012).

Here, the relation between cranial morphology, with emphasis on the bill and its relation to the braincase, and several aspects of feeding habits in penguins and other aquatic birds was analyzed through geometric morphometrics using a large dataset including fossil and extant taxa. These analyses allow us for the first time to offer a quantitative approach to infer the 
diet of extinct penguins and compare the morphology of living and fossil penguins with other diving birds and core waterbirds, identifying trends and differences among most of the known seabirds in relation to their feeding strategies.

Institutional Abbreviations.-IB/P/B, Institute of Biology, Uniwersytet w Białymstoku, Bialystok, Poland; MPEF-PV, Museo Paleontologico Egidio Feruglio, Trelew, Argentina; MUSM, Museo de Historia Natural de la Universidad Nacional de San Marcos, Lima, Peru; OM GL, Otago Museum, Dunedin, New Zealand; SDSNH, San Diego Natural History Museum, San Diego, USA; SMNK-PAL, Staatliches Museum für Naturkunde Karlsruhe, Karlsruhe, Germany; USNM, United States National Museum (Smithsonian Institution), Washington, USA.

\section{Materials and Methods}

Dataset.-To study the cranial diversity among penguins and in relation to other waterbirds, the skulls of 118 aquatic species (Supplementary Table 1) were analyzed, emphasizing bill morphology using two-dimensional geometric morphometrics. This dataset includes most of the extant penguin species (17 species) plus five fossil taxa for which reasonably well-preserved skulls are known: Inkayacu paracasensis (MUSM 1444), Icadyptes salasi (MUSM 897), Madrynornis mirandus (MPEF-PV 100), S. urbinai (SMNK-PAL 3978), and S. megaramphus (MUSM 175). All other extant marine core waterbirds (Gaviidae, Diomedeidae, Procellariidae, Hydrobatidae, Fregatidae, Anhingidae, Phalacrocoracidae, Sulidae, and Pelecanidae) are also represented, along with tropicbirds (Phaethontidae) and nonAequornithes specialized in pursuit diving such as grebes (Podicipedidae) and auks (Alcidae). Six additional fossil taxa were also included to capture the morphological spectrum covered by extinct seabirds: Hesperornis regalis (Hesperornithiformes), Mancallinae indet. SDSNH 25236 (pan-Alcidae), Miocepphus blowi (Alcidae), Prophaethon shrubsolei (stem Phaethontidae), Limnofregata azygosteron (stem Fregatidae), and Rupelornis brodkorbi (stem Procellariiformes).
The full dataset is based on a compilation of pictures of skulls without ramphotheca in lateral view, some of which were downloaded from the online libraries Digital Morphology (2002-2019), Virtual Zooarchaeology of the Arctic Project (2010-2019), Seabird Osteology (2002-2013), and Bird Skull Collection (20002017). Lateral views have been used in order to include as many fossil specimens as possible, many of which are poorly preserved in dorsal view. Published drawings and reconstructions of fossil material were used for Limnofregata (Olson 1977), Prophaethon (Harrison and Walker 1976), Hesperornis (Bühler et al. 1988), and Mancallinae SDSNH 25236 (Smith 2011), whereas published pictures were used for Miocepphus (Wijnker and Olson 2009). Pictures were also used for S. urbinai and S. megaramphus, whereas reconstructions were produced based on high-resolution pictures for the remaining fossil taxa (Fig 1). Although the accuracy of reconstructions based on partial or distorted specimens can be subject to debate, they offer a broad approximation of the skull shape of fossil taxa that cannot be otherwise analyzed.

Independent analyses were run for three subsets of taxa: (1) penguins only, (2) pursuit divers, and (3) Aequornithes plus Phaethontiformes. This partition was made to allow for easier visualization of the resulting morphospace occupied by penguins and their relation to other aquatic birds that use the same feeding strategy (pursuit diving) and within the same large ecological/phylogenetic assemblage (marine core waterbirds).

Classifiers.-Clade membership, foraging tactics, and primary diet were defined for each extant species based primarily on del Hoyo et al. (2015) and used as classifiers (Supplementary Table 1). The use of these partitions not only allows the comparison between each group, but it can also allow the classification of fossil taxa of unknown membership (see below). Because aquatic birds are often flexible in their foraging strategies and diet, it is important to remember that these are overall categories that summarize broad biological spectrums.

The Aequornithes were divided into seven foraging-tactic groups based on a modified version of Ashmole's (1971) categories, accounting for some biomechanical specializations: 
(1) pursuit diving, (2) pursuit plunging, (3) plunging, (4) scooping, (5) surface seizing, (6) surface seizing/plunging, (7) hydroplaning/ surface filtering, (8) pattering/dipping, (9) dipping, and (10) ground predation/scavenging. The first category includes those birds that capture their prey by chasing it underwater (e.g., penguins), whereas the second is used for those which do so after plunging from the air (e.g., shearwaters). "Plunging" is restricted to birds that hunt by plunge diving from more than $20 \mathrm{~m}$ high, catching their prey deep in the water with little or no pursuit (e.g., boobies). Scooping refers to the capture of individual or multiple prey at or near the water surface, through the use of an expandable throat pouch (e.g., pelicans). Surface seizing is catching the prey near the water surface during swimming (e.g., Bulwer's petrel), whereas those classified as "surface seizing/plunging" can also do so after low plunging (e.g., albatrosses). Hydroplaning/surface filtering is the capture of zooplankton by filtering water, either swimming at the surface or during hydroplaning (movement in partial contact with water) (e.g., prions). Pattering/dipping is picking the prey at the water surface while moving the feet on the water's surface and holding steady above it (pattering) and/or low flight) (e.g., storm petrels), whereas dipping is picking the prey at the water surface during low and usually slow flight (e.g., frigatebirds). Finally, ground predation/scavenging applies to those that catch prey and/or carrion on land (e.g., giant petrel).

Primary diet items were divided into four groups: (1) fish and/or cephalopods, (2) fish and arthropods, (3) zooplankton, and (4) omnivore/opportunist. The first category includes birds that consume fast nektonic prey such as fish and squids, whereas the second one includes those that feed on fish and a wide range of non-pelagic arthropods (e.g., crabs, crayfish, and aquatic insects). Though most of these species complement their diet with nektonic prey, "zooplankton" was use for those species in which there is a regular consumption of planktonic animals. Finally, the classifier omnivore/opportunist category, which describe dietary habits instead of dietary items, is reserved for those that regularly feed on items included here in separated categories and that may also include carrion, eggs, and chicks among others.

One additional ecological classifier analyzed using the penguins-only subset was foraging area. This refers to the foraging distance penguins travel with respect to the colony, for which the arrangement of Croxall and Davis (1999) that separates penguins into (1) inshore and (2) outshore foragers was used. The first group feed close to their breeding colonies ( $<50 \mathrm{~km}$ during incubation) and tend to be sedentary, whereas the second travel longer distances and are typically migratory, returning to their colonies only for breeding and molting. Extant species were assigned to each group based on the classification presented by Davis and Renner (2003) (Supplementary Table 2).

Morphometric Analysis. - Cranial geometry was captured using the program tps.Dig2 (Rohlf 2005) to plot nine homologous landmarks of type 1 and 2 (sensu Bookstein 1991) (Fig. 2A). The landmark dataset covers the main vertices of the bill (1 to 3 ) along with the general shape of the braincase (4 to 9). These landmarks have been chosen to allow the inclusion of a broad spectrum of taxa and fossils with different states of preservation, and its placement has been carefully checked. Considering the strong correlation assumed between bill shape and foraging tactics, this element has been captured in detail using 60 semilandmarks to accurately represent its edges (tomial, culminal, and caudal). The semilandmarks were treated as sliders (chord-min $\mathrm{d}^{2}$ ) and, along with the landmark coordinates, superimposed using generalized Procrustes analysis in tps.RelW (Rohlf 2003).

Next, the Procrustes coordinates were subjected to a principal component analysis (PCA) using MorphoJ (Klingenberg 2011), and the resulting PC scores underwent linear discriminant analysis (LDA) using PAST 3.06 (Hammer et al. 2001) to test how distinctive each classifier group is from the others. The latter analysis (LDA) can also classify specimens of unknown membership (i.e., fossil taxa), assigning each point to the group that gives minimal Mahalanobis distance to its mean. LDA jackknifed percentages of correctly classified points using different series of PC scores explaining $90 \%, 95 \%$, and $99 \%$ of the cumulative variance 


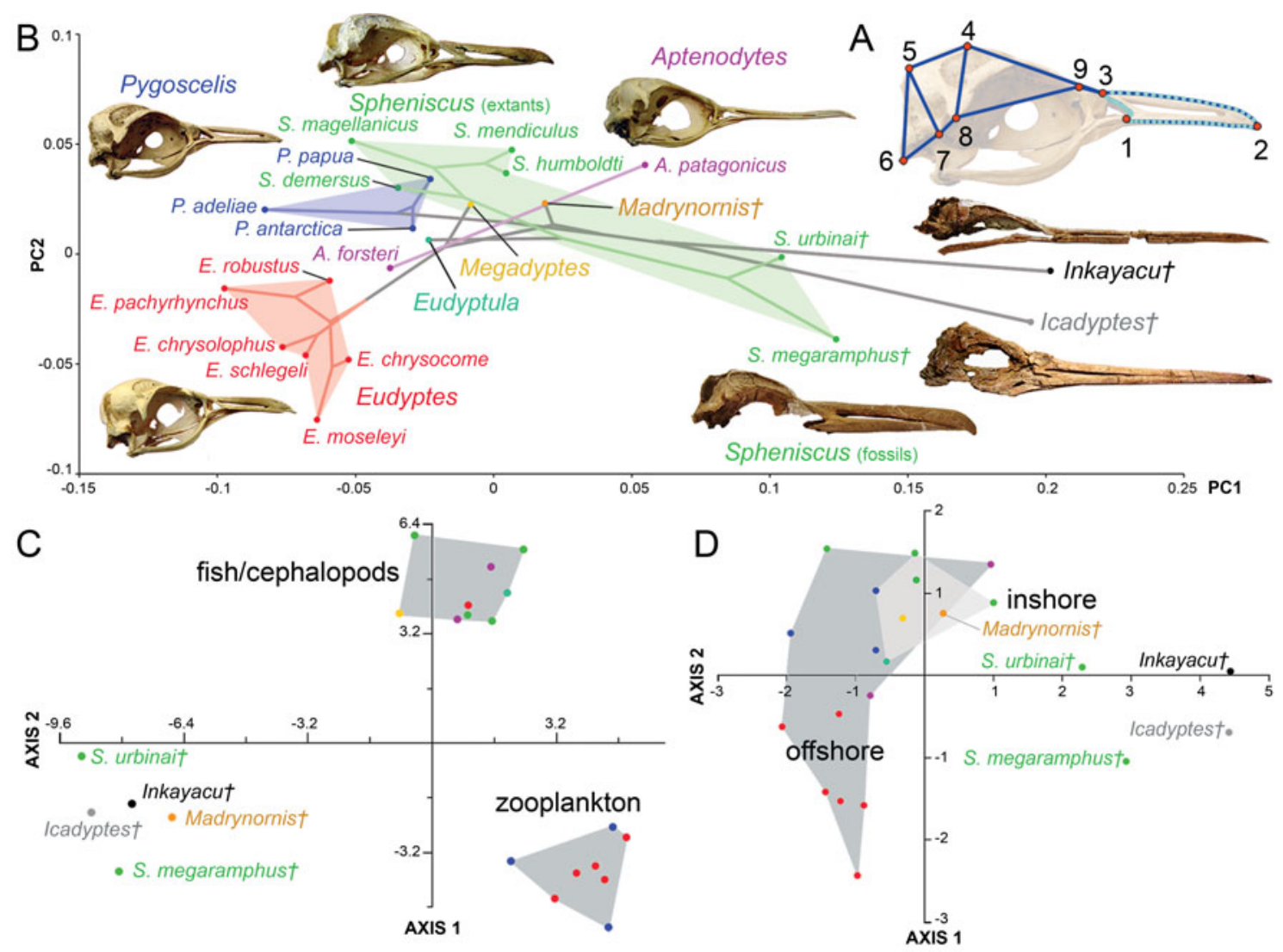

FIGURE 2. Analysis of skull shape disparity among penguin genera. A, Position of landmarks on seabird skulls. Landmark definition: 1, caudal end of the rostrum tomial edge; 2 , premaxillary symphysis at the tip of the rostrum; 3 , nasofrontal hinge; 4 , highest point of the braincase; 5 , dorsal end of the transversal nuchal crest; 6 , ventral tip of the paraoccipital process; 7, squamosal cotyla for the quadrate cranial-most edge; 8, postorbital process tip; 9, caudal-most edge of the joint between nasal and lacrimal. B, Twodimensional morphospace with phylogenetic mapping based on the first two principal component (PC) axes. C, Distinctiveness among primary diet groups on the morphospace defined by the first two linear discriminant analysis (LDA) axes and relative distribution of unclassified fossil taxa. D, Distinctiveness among foraging distance groups on the morphospace defined by the first two LDA axes and relative distribution of unclassified fossil taxa. 
were compared to identify the optimum performance for each classifier (Supplementary Table 3). Additionally, each optimal series of PC scores was examined using nonparametric multivariate analysis of variance (one-way NPMANOVA) with 10,000 permutations and Euclidean distances in PAST 2.17c. All singletons and specimens of unknown membership were excluded for this test. The resulting $F$-statistic and Bonferroni corrected $p$-values show any significant differences in the distribution of each group without requiring normality of the multivariate data.

Finally, to evaluate the correlation between skull morphology and phylogenetic signal, a phylogenetic tree was mapped into the morphospace using unweighted squared change along with a permutation test $(10,000$ permutations) in MorphoJ. The resulting $p$-value indicates whether a strong phylogenetic signal is present. For this test, an informal supertree was assembled based on several published phylogenetic analyses: Neornithes (Jarvis et al. 2014), Podicipedidae (Ksepka et al. 2013), pan-Alcidae (Smith and Clarke 2015), Gaviidae (Sprengelmeyer 2014), Pelecaniformes/Suliformes (Smith 2010), Sulidae (Patterson et al. 2011), Phalacrocoracidae (Kennedy and Spencer 2014), Pelecanidae (Kennedy et al. 2013), Sphenisciformes (Degrange et al. 2018), and Procellariiformes (Kennedy and Page 2002) (Supplementary Fig. 1).

\section{Results}

Morphospace Occupation and Feeding Strategies among Penguins.-The shape variation in penguin skulls is summarized here by $21 \mathrm{PC}$ axes, with the first four explaining $90 \%$ of the total variance and most shape disparity captured by the first two $(80.5 \%)$. The first PC mainly describes the proportion between braincase size and bill length; whereas the second PC describes the position of the braincase with respect to the tomial edge of the bill, as well as the general bill sinuosity (Supplementary Fig. 2A). The third PC axis is related to the dorsoventral compression of the braincase, particularly the thinness of the beak, while the fourth is related to the shape of the anterorbital frontal process and the caudal shape of the maxilla.
Despite some potential overlap close to the central region of the plot, the space occupied by each genus is well defined by the first two axes (Fig. 2B). This taxonomic partition of the morphospace suggests a strong correlation between skull morphology and phylogeny, which has been confirmed by the highly significant $p$-value $(<0.0001)$ obtained by the permutation test. Whereas all extant taxa, except for the king penguin (Aptenodytes patagonicus), are placed on the negative side of the first PC axis, fossil taxa occupy the positive side; with Inkayacu and Icadyptes plotting far from the extant taxa and S. urbinai and S. megaramphus placed in an intermediate position due to their longer beaks and proportionally smaller braincases. Madrynornis plot on the positive side closer to the morphospace origin. Although distribution along the second axis seems to be more equitable, extant genera tend to occupy the positive side; except for Spheniscus, whose fossil species plot on the horizontal axis and negative side, and Eudyptes, which is entirely restricted to the negative side. The emperor penguin, Inkayacu, and Icadyptes also plot on the negative side, whereas Madrynornis fell in the positive side at the same level as the yellow-eyed penguin Megadyptes.

LDA and NPMANOVA were also used in order to quantify the distinctiveness between the areas occupied by each penguin genus. The highest percentages of correctly classified points were obtained using the first seven PC axes (Supplementary Table 3). The first two LDA canonical axes allow a clear separation of each genus (Supplementary Fig. 3), except for Madrynornis, which overlaps with Eudyptes, though the percentage of successful classification is $72 \%$. Three of the fossil taxa analyzed have been misclassified by the jackknife test, which is unable to distinguish Inkayacu from Icadyptes, and Madrynornis from Eudyptes. On the other hand, the pairwise NPMANOVA values for the four polytypic genera show that Eudyptes is the only one that is significantly different $(F=6-8.4, p$-values $<0.05)$. The significance of such differences is lost when the $p$-values are Bonferroni corrected.

Only two primary diet categories were identified for penguins: (1) fish and/or cephalopods and (2) zooplankton. The best 
TABLE 1. Feeding strategies inferred for fossil penguins. The group identity for each taxon is based on jackknifed linear discriminant analysis (LDA) classification using different taxonomic samples. Percentages of correctly classified points are also jackknifed.

\begin{tabular}{|c|c|c|c|}
\hline \multirow{3}{*}{$\begin{array}{l}\text { Taxonomic sample } \\
\% \text { Correctly classified points }\end{array}$} & \multirow{3}{*}{$\begin{array}{l}\text { Foraging area } \\
\text { Penguins } \\
77.3\end{array}$} & \multicolumn{2}{|c|}{ Primary diet } \\
\hline & & Penguins & Aequornithes \\
\hline & & 81.8 & 67.7 \\
\hline Inkayacu & - & Fish/cephalopods & - \\
\hline Icadyptes & - & - & Fish/cephalopods \\
\hline Madrynornis & Inshore & Zooplankton & - \\
\hline Spheniscus urbinai & - & - & Fish/cephalopods \\
\hline
\end{tabular}

performance for this classifier was achieved using the first 14 PC axes, and the NPMANOVA show that the skulls of penguins preying on these dietary items are significantly different $(F=4.2$, Bonferroni $p$-value $=0.01)$. The first two LDA canonical axes allow a clear discrimination between both primary diets (Fig. 2C), recovering $81.8 \%$ of correctly classified points. The analysis is able to classify only two fossil taxa using these dietary categories (Table 1), identifying Inkayacu as a possible predator of fish and/or cephalopods (e.g., squids) and Madrynornis as a likely consumer of zooplankton. Following analyses including additional groups of seabirds were unable to confirm or offer alternative assignments for these taxa, but the round including all sampled Aequornithes classified Icadyptes and S. urbinai as hunters of fish and/or cephalopods with $68 \%$ effectiveness.

Foraging area is the only classifier whose optimal performance was reached using the first two PC axes. Based on the NPMANOVA, it seems that the skulls of penguins with different foraging areas are indeed significantly different $(F=5.3$, Bonferroni $p$-value $=0.02)$. Although both groups seem to overlap when the first two LDA canonical axes are used (Fig. 2D), mostly due to the position of the emperor penguin, the analysis is able to correctly classify $77.3 \%$ of the samples. Madrynornis is the only fossil taxon classified by the analysis (Table 1), being identified as a potential inshore forager.

Cranial Disparity among Pursuit Divers.-The skull disparity among aquatic birds specialized in underwater pursuit is captured here by 63 PC axes, with $90 \%$ of the total variance explained by the first seven axes, and the first two accounting for more than half of the variation $(68.9 \%)$. The first PC is related to the dorsoventral compression of the braincase along with bill length and thinness; whereas the second PC describes the braincase length and bill narrowing (Supplementary Fig. 2B). The third PC axis, which contributes to explain $8.8 \%$ of the variability, is related to the dorsoventral expansion of the braincase and the constriction of the bill at its middle point; while the fourth is related to the size of the braincase and the broadening of the bill, accounting for $5 \%$ of the variability.

A strong correlation between skull morphology and phylogeny is confirmed among pursuit divers by the highly significant $p$-value $(<0.0001)$ obtained through the permutation test. Most families occupy a wide but relatively narrow part of morphospace, with different degrees of overlap defined by the first two PC axes (Fig. 3A). The family Anhingidae, here represented only by the American darter (Anhinga anhinga), fell within the space occupied by the closely related cormorants and shags (Phalacrocoracidae), forming the most distinctive cluster, which is completely isolated from all remaining families. Auks (panAlcidae) and penguins occupy the largest areas, being adjacent to each other and partially overlapping. However, most of the overlap occurs close to the positive side of the first PC axis, and it is caused by extinct taxa of both families, such as S. urbinai and the great auk (Pinguinus impennis). Once again, Inkayacu and Icadyptes plot far from all other penguins, reaching an area uncovered by any other pursuit diver lineage.

During all LDAs, the highest percentages of correctly classified points were obtained using the first 26 PC axes (Supplementary Table 3). The first two LDA canonical axes allow a 


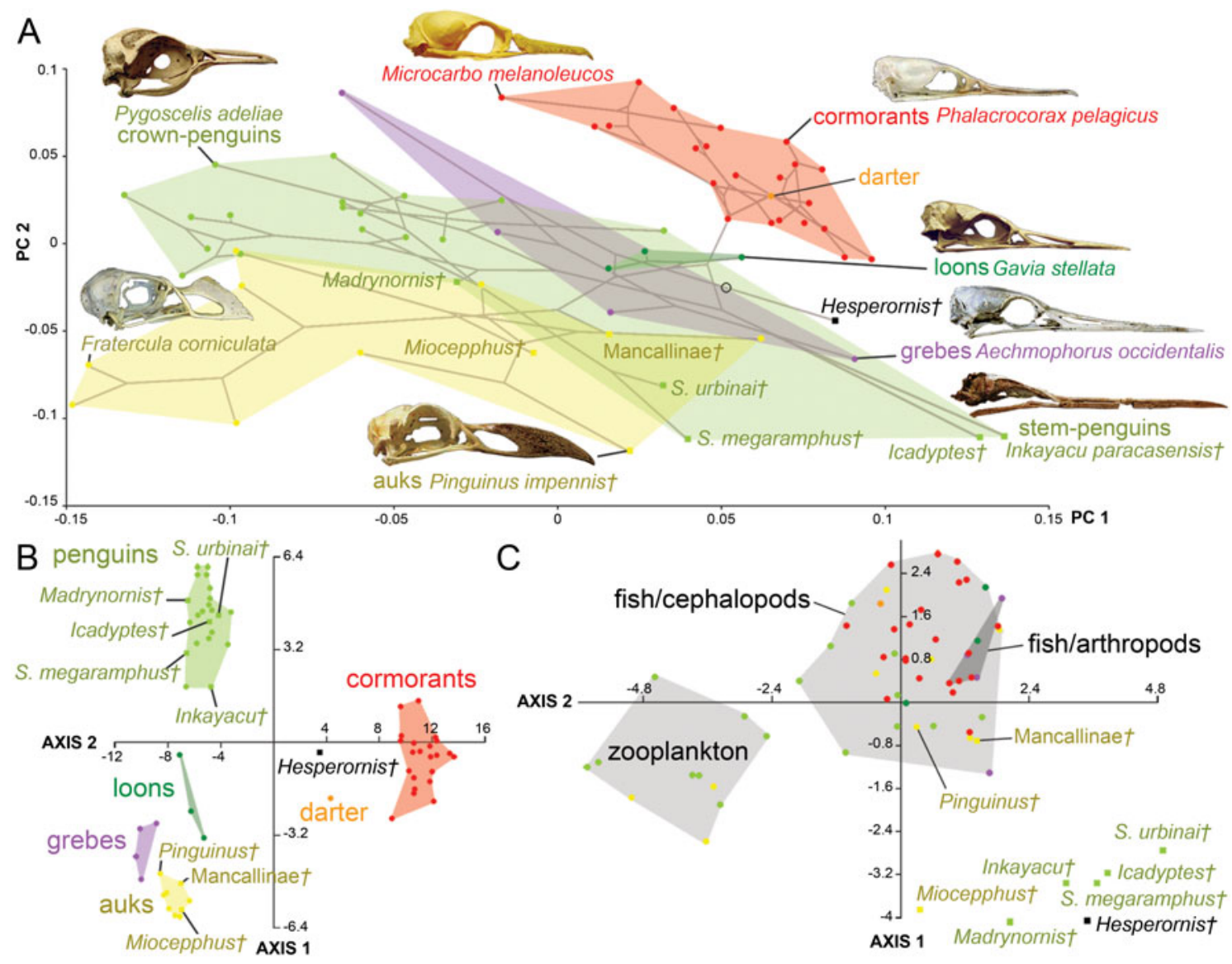

FIGURE 3. Skull shape disparity among pursuit diving birds. A, Taxic partition of morphospace at level of families for pursuit divers with phylogenetic mapping, based on the first two principal component (PC) axes. B, Distinctiveness among families on the morphospace defined by the first two linear discriminant analysis (LDA) axes. C, Distinctiveness among primary diet groups on the morphospace defined by the first two LDA axes. 
clearer discrimination of each family (Fig. 3B), with penguins occupying the second quadrant and auks in the third quadrant along with grebes and loons. The analysis could recover $90.6 \%$ of correctly classified points, erroneously classifying 6 of the 64 analyzed species. All fossil taxa were correctly classified in terms of morphospace, except for Inkayacu, which was erroneously attributed to pan-Alcidae. Nevertheless, the pairwise NPMANOVA values shows that cormorants are the only group significantly different $(F=4.7-22.3, \quad p$-values $<0.05)$ from all other families represented by more than a single observation. Auks also show significant differences from penguins $(F=5.7, p$-value $=0.02)$, but not from grebes or loons.

Three primary diet categories are observed among pursuit divers: (1) zooplankton, (2) fish and/or cephalopods, and (3) fish and arthropods. The NPMANOVA shows that the skulls of diving birds that consume mostly zooplankton are significantly different from those of diving birds that prey on fish and nonpelagic arthropods $(F=5.6, p$-value $<0.001)$, and particularly from those of diving birds that prey on fish and/or cephalopods $(F=10.8$, $p$-value $<0.001)$. However, there are no significant differences between piscivorous species that complement their diets with arthropods and those that prefer cephalopods. This is also reflected by the first two LDA canonical axes, which allow a clear discrimination between zooplankton and fish consumers, but not between each piscivorous group (Fig. 3C). This analysis could classify two of the fossil taxa included with $67.2 \%$ effectiveness (Table 2), identifying the auk Miocepphus blowi as a possible consumer of zooplankton and the Mancallinae indet. SDSNH 25236 as a likely predator of fish and/or cephalopods.

Cranial Disparity and Feeding Strategies among Core Waterbirds.-The skull disparity among marine Aequornithes plus tropicbirds is captured by 98 PC axes, with ca. $90 \%$ of the variance explained by the first six axes, and the first two accounting for most of the shape variation $(73.3 \%)$. The first PC mainly describes a reduction in braincase size correlated with an increase in bill elongation, whereas the second PC describes the dorsoventral compression of the braincase and caudal migration of the paraoccipital process along with bill narrowing (Supplementary Fig. 2C).

As in all the analyses, the permutation test shows a strong correlation $(p$-value $<0.0001)$ between skull morphology and phylogeny. In the case of the morphospace defined by the first two axes (Fig. 4A), most of the observed overlap occurs close to the origin and on the horizontal axis. Unsurprisingly, families represented by a single genus, such as loons and pelicans (Pelecanidae), occupy the smallest morphospaces. However, loons are placed close to the origin overlapping with other groups (e.g., petrels, penguins), whereas pelicans plot far from all other Aequornithes, because of high positive PC 1 scores related to their hyperelongated beaks. Similarly, the only storm petrel included here, Oceanodroma tethys, occupies an isolated region of morphospace in the third quadrant, due to its unusually high negative scores on both axes.

As in the case of pursuit divers, cormorants and shags form one of the most distinctive families of Aequornithes, being completely isolated on the positive side of the second PC axis. Despite being constrained to a relatively narrow area along the second PC axis, penguins occupy the widest areas when stem taxa are included. Whereas Madrynornis and all extant taxa are placed on the negative side of the first PC axis, the remaining fossil penguins occupy the positive side approaching the spaces occupied by tubenoses (i.e., albatrosses) and frigatebirds. Petrels and allies (Procellariidae) occupy the largest area overall, with shearwaters (Puffinus and Callonectris) spread close to the horizontal axis, and all remaining genera occupying the negative side of the second axis in the third quadrant, except for the giant petrel (Macronectes giganteus), which crosses to the fourth quadrant.

The optimal performance on all LDAs was achieved using the first 29 PC axes (Supplementary Table 3). In general, the first two LDA canonical axes allow a clear separation of each family (Supplementary Fig. 3B), although there is some overlap between penguins, pelicans, tropicbirds, and loons in the second quadrant. The analysis recovers $87 \%$ of correctly classified points, erroneously 
TABLE 2. Feeding strategies inferred for non-penguin fossil seabirds. The group identity for each taxon is based on jackknifed linear discriminant analysis (LDA) classification using different taxonomic samples. Percentages of correctly classified points are also jackknifed.

\begin{tabular}{llll}
\hline \hline & & Primary diet & Foraging tactics \\
\hline Taxonomic sample & Divers & Aequornithes & Aequornithes \\
\% Correctly classified points & 67.2 & 67.7 & 78.8 \\
Mancallinae indet. & Fish/cephalopods & - & - \\
Miocepphus & Zooplankton & - & - \\
Prophaethon & - & - & Pursuit diving \\
Limnofregata & - & Fish/arthropods & - \\
Rupelornis & - & Zooplankton & Pursuit plunging \\
\hline
\end{tabular}

classifying 13 of the 99 analyzed species. The pairwise NPMANOVA values show that tropicbirds and loons are not significantly different from any other family of Aequornithes, whereas frigatebirds are only significantly different $(F=15.2, p$-value $=0.03)$ from cormorants. All remaining families are significantly different from one another to different degrees $(F>8, p$-values $<0.05)$, except for albatrosses with respect to pelicans, which, despite having a high $F$-value, do not show significant differences after Bonferroni correction $(F=29$, $p$-value $=0.08$ ).

Similar to the results obtained for diving birds, the NPMANOVA shows that the skull of zooplankton-eating Aequornithes is significantly different from those preying on fish and/or cephalopods ( $F=16.7, \quad p$-value < 0.001 ) and from omnivorous or opportunist taxa $(F=4, p$-value $=0.01)$. Yet, no significant differences were identified between any of the piscivorous categories (i.e., fish/cephalopods, fish/arthropods) and omnivore/opportunist taxa (Fig. 4B). The analysis is only able to classify two of the non-penguin fossils included (Table 2), classifying Limnofregata as a possible consumer of fish and non-pelagic arthropods, and Rupelornis as a likely zooplankton eater.

This dataset also offers an opportunity to test whether foraging tactics in waterbirds can be recognized based on cranial morphology. The pairwise NPMANOVAs show that the skulls of waterbirds that feed by surface seizing or filtering (with or without hydroplaning) are not significantly different from those of other groups (Table 3). Overall, birds that feed by scooping (i.e., pelicans) or pursuit diving seem to have the most distinctive skulls among Aequornithes, being significantly different from those of birds with the other four foraging tactics. Pursuit divers show significant differences from those that feed by scooping $(F>36, p$-values $<0.008)$ and a combination of surface seizing and plunging ( $F>6, p$-values $<0.02$ ), being also identified as significantly different from dipping $(F=7.1, p$-value $=0.02)$ and high plunging birds $(F=7.1, p$-value $=$ 0.01 ). This dataset allows a clear visual discrimination of each foraging tactic using the first two LDA axes (Fig. 4C), also recovering a high percentage of correctly classified points $(78.8 \%)$. Only two of the fossils included for which the foraging tactic is unknown were classified (Table 2): Rupelornis as a likely hunter by pursuit plunging, and Prophaethon as a possible pursuit diver.

\section{Discussion}

Morphological Trends among Penguins and Waterbirds.-As has been mentioned, there is clear evidence of a major change in the body plan of penguins during their evolution in relation to their skull morphology and beak in particular. The first PC axis shows that most of the skull variance in penguins is indeed linked to changes in bill length, as is also the case among Aequornithes (Supplementary Fig. 2C). However, these results also show that bill length is inversely correlated with braincase size, so the hyperelongated spear-like bill of stem penguins results in a proportionately smaller braincase. Accordingly, the braincase of giant penguins like Inkayacu is not much larger than in some extant penguins, despite being considerably longer. This is one of the main distinctions between the skull of Paleogene penguins and extant species of the genus Aptenodytes. A similar trend between rostrum and braincase has been 


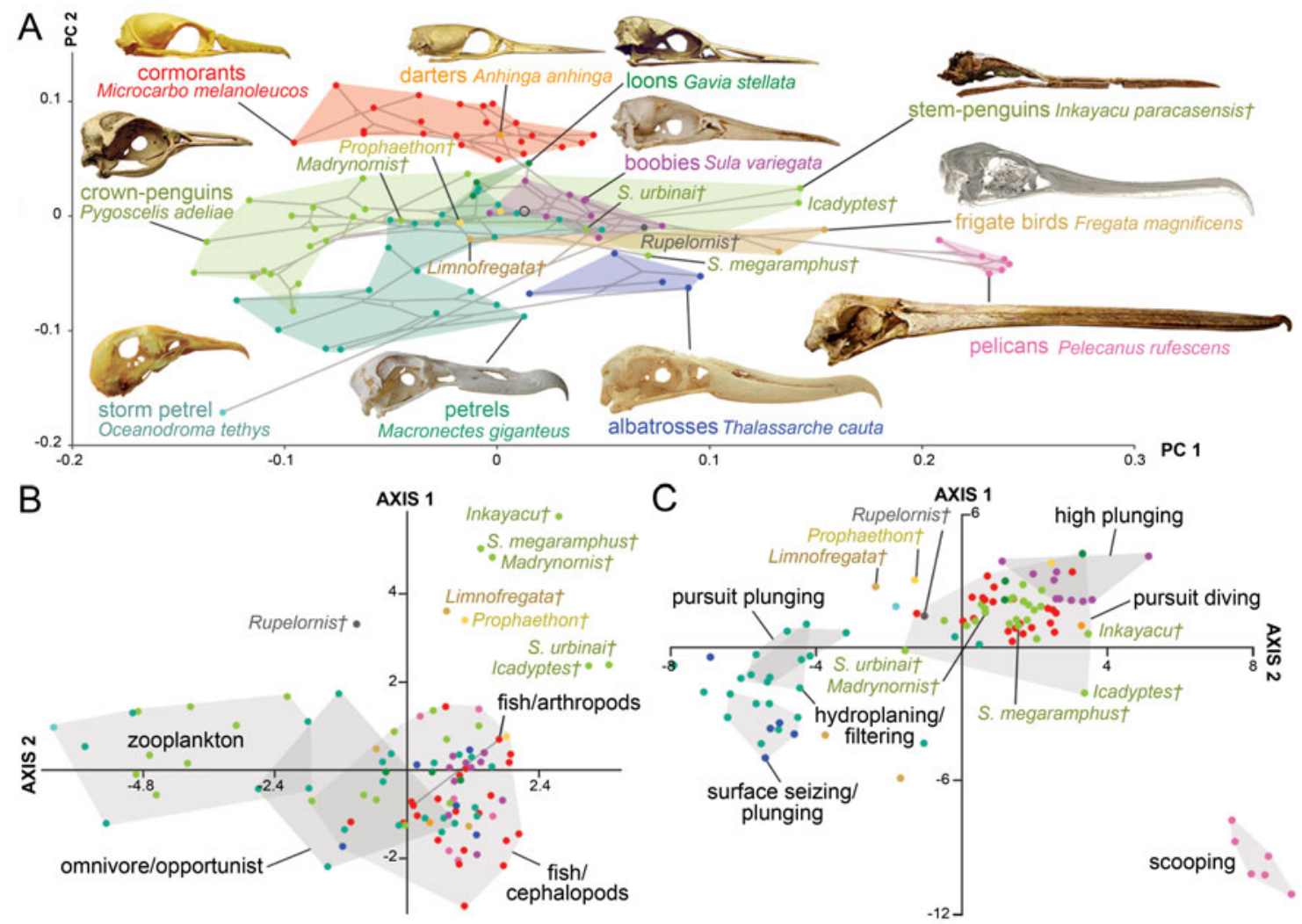

FIGURE 4. Skull shape disparity among Aequornithes families plus tropicbirds (Phaethontidae). A, Two-dimensional morphospace with phylogenetic mapping based on the first two principal component (PC) axes. B, Distinctiveness among primary diet groups on the morphospace defined by the first two linear discriminant analysis (LDA) axes. C, Distinctiveness among foraging tactic groups on the morphospace defined by the first two LDA axes. 
TABLE 3. Results of nonparametric multivariate analysis of variance (NPMANOVA) verifying the differences in seabird skull shape based on foraging tactics. F-values from the analysis of the Aequornithes-only subset excluding singletons. Statistically significant values (Bonferroni-corrected $p$-value $>0.05$ ) are shown in bold. Higher $F$-values indicate larger differences.

\begin{tabular}{|c|c|c|c|c|c|c|c|c|}
\hline & $\mathrm{S}$ & $\mathrm{P}$ & $\mathrm{D}$ & SS & $\mathrm{SS} / \mathrm{P}$ & PD & PP & $\mathrm{H}$ \\
\hline Scooping $(S)$ & - & & & & & & & \\
\hline Plunging $(\mathrm{P})$ & 66.9 & - & & & & & & \\
\hline Dipping (D) & 6.2 & 13 & - & & & & & \\
\hline Surface seizing (SS) & 15.2 & 5.4 & 2.5 & - & & & & \\
\hline Surface seizing/plunging (SS/P) & 36.3 & 7.1 & 5 & 0.7 & - & & & \\
\hline Pursuit diving (PD) & 43.1 & 7.1 & 7.1 & 2.7 & 9.5 & - & & \\
\hline Pursuit plunging (PP) & 88.4 & 15.3 & 19.5 & 3.6 & 4.7 & 3.2 & - & \\
\hline Hydroplaning/surface filtering $(\mathrm{H})$ & 40 & 15 & 10.8 & 0.2 & 2 & 8.3 & 4.6 & - \\
\hline
\end{tabular}

observed in theropod skulls (Marugán-Lobón and Buscalioni 2003; Foth and Rauhut 2013), which contrasts with the results of MarugánLobón and Buscalioni (2004, 2006), who found that the length of both elements change mostly independently in modern birds, with the bill orientation being identified as a major driver of changes in braincase morphology. In penguins, this aspect is part of second PC axis, which relates to variations in the overall shape of the bill and the relative position of the braincase, so that when the braincase is placed above the tomial edge of the bill, the culmen becomes more concave and its tip more hooked, as seen in banded penguins (Spheniscus). Zusi (1975) identified these differences in the position of the bill in penguins based on its position relative to the basitemporal plate, suggesting that such variations may reflect the angle at which the bill is held during foraging, based on the work of Duijm (1951). The second PC axis of Aequornithes shows similar changes related to bill orientation paired with an overall thinning of the skull.

Although some methodological differences are likely to contribute to the differences between studies (e.g., selection and coverage of landmarks, here with an emphasis on bill morphology over braincase), taxonomic sampling is certainly an important cause of these differences. Banded penguins are considered extreme examples of the skull defined as type 1 or orthocranial (Marugán-Lobón and Buscalioni 2004), in which the bill is held horizontally and the foramen magnum is vertical, being very straight overall (Duijm 1951; Hofer 1952). This seems to be the most common condition not only in penguins but also among other aquatic birds such as cormorants and darters. Interestingly, none of these correlations seems to play a major role in the case of the main components explaining the variation on pursuit divers, in which the elongation and thinning of the bill correlate with a dorsoventral compression of the braincase instead (Supplementary Fig. 2B).

Another important factor that may be contributing to this pattern is the "Pinocchio effect" (e.g., Siegel and Benson 1982; Hallgrimsson et al. 2015). When much of the variation is restricted to a few landmarks or even to a single landmark, the Procrustes superimposition tends to spread variation from landmarks with greater variation to landmarks with less variation. Because superimposition scales all shapes to the same centroid size, the extreme elongation of one part of the form (e.g., beak) will reduce the overall size of it. This means that for individuals with identical braincase sizes but different beak sizes, the braincase will appear relatively smaller in those individuals with longer beaks. While the Pinocchio effect is not usually considered a major problem in studies aiming to describe or test differences between groups (e.g., species) (Tatsuta et al. 2018), it is relevant when discussing the shape deformation itself. Although the use of semilandmarks helps to mitigate this artifact by spreading the variation of the beak across multiple points, this effect may partially influence the pattern observed in penguins and core waterbirds. Therefore, the impact of bill hyperelongation in the morphological trends of bird skulls overall must be assessed taking this potential bias into account. 
Taxic Occupation of Morphospace and Possible Analogues for Extinct Penguins.-Although all permutation tests show strong correlations between skull morphology and phylogeny, this is not necessarily reflected in a perfect taxic partitioning of the morphospace. For instance, while there seems to be a good separation of the space occupied by each penguin genus when the first two PC axes are plotted (Fig. 2B), the NPMANOVA values show no significant differences between the four polytypic extant genera (i.e., Aptenodytes, Pygoscelis, Eudyptes, and Spheniscus). This appears to reflect the proximity and partial overlapping between most extant genera, particularly close to the origin, which seems to be mainly caused by the wide area covered by Spheniscus following the inclusion of its fossil species. Nevertheless, the first two LDA axes allow a clear discrimination of each genus (Supplementary Fig. 3A), except for Madrynornis from Eudyptes, and they are also able to correctly classify $72 \%$ of the species. It is also noteworthy that sympatric taxa tend to occupy separate areas in the PC morphospace, as in the case of the Antarctic genera Aptenodytes and Pygoscelis or the species that regularly breed in the Falkland Islands (i.e., A. patagonicus, Pygoscelis papua, Eudyptes chrysocome, Eudyptes chrysolophus, and Spheniscus magellanicus).

The analyses also show that Madrynornis and all extant penguins occupy a different region of morphospace, not only from the giant Eocene Inkayacu and Icadyptes, as would be expected, but also from S. urbinai and S. megaramphus due to their shorter beaks and larger braincases. Although the king penguin (A. patagonicus) is the only extant species approaching the cranial proportions of these fossil taxa, it is clearly not a close analogue of these extreme morphologies. The extant great penguins have thinner and shorter bills along with proportionally larger braincases, as is reflected in their position in the morphospace defined by the first two PC axes (Fig. 2B).

A similar separation between stem and crown penguins was identified based on the dorsal morphology of the braincase (Acosta Hospitaleche 2011), although $S$. urbinai and $S$. megaramphus do not seem to be different from the extant banded penguins based only on this region of the skull. This partition between fossil and living penguins suggests that these extinct taxa were exploring very different feeding methods and/or prey from their extant counterparts. Whereas most modern penguins fill a morphospace region largely unexplored by other Aequornithes (Fig. 4A), Spheniscus paleospecies invade the space occupied by extant boobies, shearwaters, and albatrosses, and stem penguins approach the region occupied by extant frigatebirds. A similar distribution is observed when penguins are compared with other pursuit divers (Fig. 3A), with little overlap between extant penguins and other diving families, and extinct taxa covering separate areas. However, the quadrant occupied by fossil penguins seems to be rarely explored by extant divers, being mostly covered by extinct flightless taxa such as Hesperonis and auks (i.e., Mancallinae and Pinguinus). Today, the thick-billed murre (Uria lomvia), grebes, and to some extent loons seem to be among the few divers filling this space, with the dagger-billed western grebe (Aechmophorus occidentalis) being the closest analogue to the spear-billed stem penguins, whereas $S$. urbinai and $S$. megaramphus seem to be more similar to the extinct Mancallinae auks and particularly to the great auk (P. impennis)

It is also worth noting that, in general, penguins and auks occupy close but distinct areas of the morphospace defined by the first two PC axes (Fig. 3A). As mentioned, most of the overlap between pan-Alcidae and Sphenisciformes is caused by extinct taxa of both families, such as P. impennis and S. urbinai. However, both the little auk (Alle alle) and Cassin's auklet (Ptychoramphus aleuticus) overlap or approach the crested penguins Eudyptes; whereas the long-billed murrelet (Brachyramphus perdix) approaches Madrynornis. These three species are the only alcids classified as zooplankton eaters, as is also the case for Eudyptes. This shows that despite often having been considered ecological analogues, living auks and penguins often have very distinct skulls, which converge only on planktivorous species and some extinct piscivorous ones.

Seizing Prey.-Olson (1985) and Myrcha et al. (1990) have proposed that the spear-like beak of stem penguins could be appropriate 
for spearing large prey underwater. Ksepka et al. (2008) described several anatomical features in Icadyptes that point to it as a speardiving specialist, including the narrow and solid bill and the robustness of the cervical vertebrae. This scenario seems to be congruent with the placement of the stem penguins in relation to other pursuit divers (Fig. 3A), particularly with the western grebe. Few extant birds hunt by spear-diving, and darters or anhingas (Anhinghidae) are by far the most specialized, capturing fish by spearing them in a similar fashion to herons after underwater stalking or pursuit (Nelson 1980). However, both loons and large grebes (e.g., Aechmophorus) are also able to spear their prey underwater during pursuit, although they can also catch it with a forceps-like motion (Lawrence 1950; LaPorte et al. 2013). Similar to giant penguins, all these birds possess pointed and elongated bony bills, which are covered in life by a relatively thin but sharp rhamphotheca that closely resembles the bone shape. Likewise, Ksepka et al. (2008) inferred that a thin rhamphotheca was present in Icadyptes, based on the vascular texturing of the bony beak. They also highlighted that other similarly hyperelongated bills found isolated in Antarctica (i.e., USNM 244152, IB/P/B-0167) seem to be less ankylosed and more lightly built than in Icadyptes. Based on direct examination, it is possible to confirm the existence of different degrees of palatal ankylosing of the premaxillae among giant penguins (Fig. 5), with Icadyptes showing the most extensive palatal closure, followed by IB/P/B-0167, which exceeds the extension observed in modern penguins, but resembles the condition in loons and great grebes in particular. In contrast, there is no palatal ankylosing in Inkayacu, suggesting the existence of different degrees of specialization among giant taxa.

Judging by its proximity to grebes (Fig. 3A) and the overall morphology of its toothless and pointed premaxillae, Hesperornis may have also used a similar feeding strategy, although the morphology of the lower jaw certainly points to some significant differences in the seizing of the prey.

In contrast, biting is the most common way to secure large prey in extant penguins (see

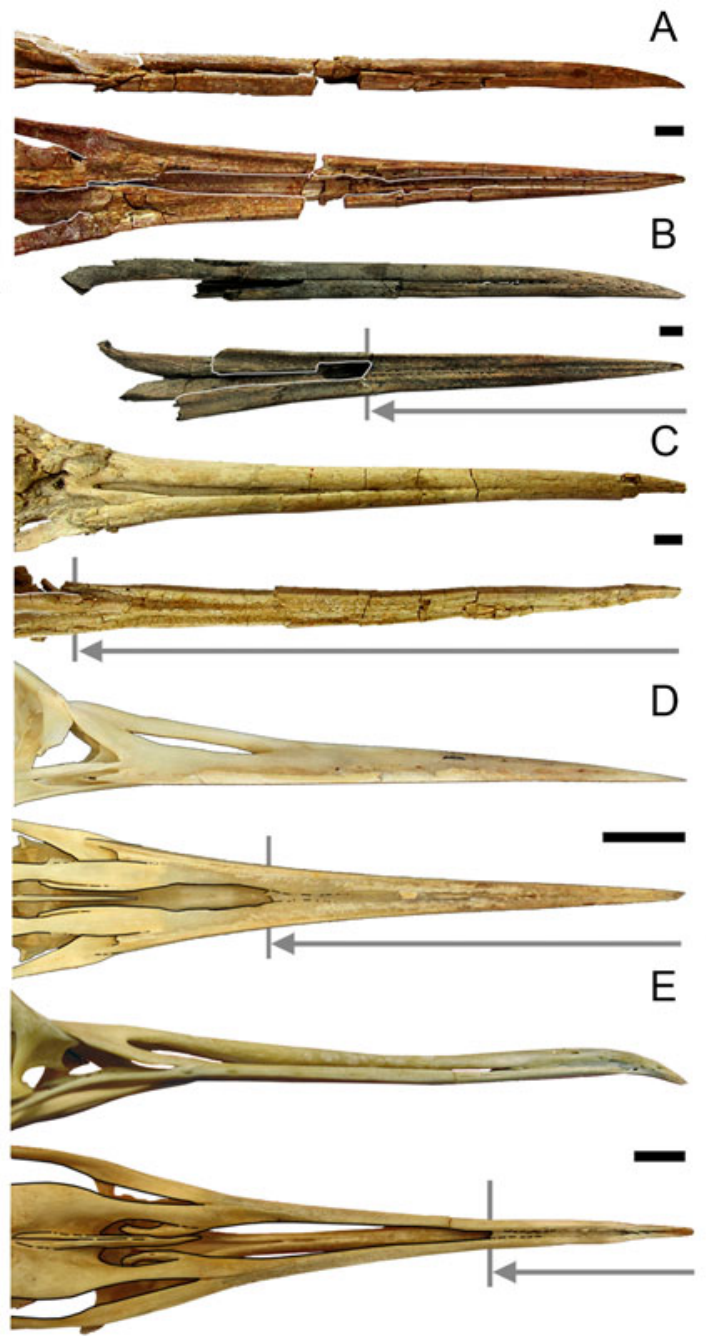

FIGURE 5. Bill comparisons in stem penguins and extant taxa in lateral (up) and ventral (down) views. A, Inkayacu paracasensis; B, cf. Anthropornis or Palaeeudyptes IB/P/ B-0167; C, Icadyptes salasi; D, western grebe (Aechmophorus occidentalis); and E, king penguin (Aptenodytes patagonicus). Gray arrow shows the caudal limit of the palatal closure. Scale bars (black), $10 \mathrm{~mm}$.

Ponganis et al. 2000), and the most specialized fish eaters (i.e., Spheniscus) develop a thick rhamphotheca, in which the tip of the upper jaw is strongly hooked and opposes an upcurved lower jaw tip (Zusi 1975). Although the tips are damaged, the exceptionally wellpreserved S. megaramphus MUSM 2087 possesses a rhamphotheca that is almost identical to that in its living counterparts. Furthermore, the holotype of $S$. urbinai also preserves 
fragments of a thick and striated rhamphotheca. These similarities, along with the overall bill and braincase morphology (Stucchi et al. 2003; Acosta Hospitaleche 2011), show that although the cranial proportions of these paleospecies are different from their extant relatives, their feeding habits were very similar to those of other banded penguins, relying on a powerful bite to catch their prey.

Inference of Feeding Habits in Fossil Penguins.-Unfortunately, and although the LDA and NPMANOVA discriminate several biological classifiers, few analyses were able to classify fossil penguins in any specific dietary or foraging-area categories due to their unusual morphology (Table 1). As has often been suggested (e.g., Olson 1985; Ksepka and Bertelli 2006; Clarke et al. 2007), the spearbilled Eocene penguins Inkayacu and Icadyptes are here identified as possible predators on fish and/or squids, which are also the most likely prey of S. urbinai. Madrynornis, on the other hand, is classified as a form that could incorporate zooplankton as a primary element in its diet. Although some studies have suggested a piscivorous diet for Madrynornis (Tambussi and Acosta Hospitaleche 2008; Degrange et al. 2018), others have proposed more opportunistic behavior (Haidr and Acosta Hospitaleche 2014). While we often classify modern penguins in discrete dietary categories for comparative purposes (Zusi 1975), in reality, most of them are opportunists that feed on schooling fish, planktonic crustaceans, and squid, eating what is available. Very few species are truly dependent on a single prey, like the king penguin (A. patagonicus), which largely specializes on lanternfish (Myctophidae), and the chinstrap penguin (Pygoscelis antarctica), which feeds mostly on Antarctic krill (Euphausia superba), but even they supplement their diet with other items (see Borboroglu and Boersma 2013). That being said, only Pygocelis and Eudyptes include planktonic crustaceans as a primary element in their diet, although both will complement them or even replace them with fish and/or squid depending on available resources. Using this broad classification, the NPMANOVA shows that the skull of penguins preying primarily on zooplankton is slightly but significantly different from those preferring larger nektonic prey like fish or squid. Although an early appearance of a planktonbased diet has been proposed based on fragmentary specimens from the Eocene of Antarctica (Jadwiszczak 2006; Haidr and Acosta Hospitaleche 2012), Madrynornis is here considered as the earliest evidence of such a diet in penguins. The LDA also classified this taxon as a possible inshore forager, which would make the Gentoo penguin (P. papua) its closest living analogue. Due to its proclivity to forage close to its breeding grounds, the Gentoo is the most opportunistic of the bush-tailed penguins, feeding on species that are patchy (Borboroglu and Boersma 2013) and with planktonic crustaceans composing $44 \%$ of its diet by weight on average, but varying from $98.4 \%$ to less than $1 \%$. This suggests that Madrynornis could indeed have been an opportunist that incorporated relatively large amounts of zooplankton in its diet, as suggested by Haidr and Acosta Hospitaleche (2014).

\section{Conclusions}

Most Paleogene penguins reached larger sizes than their extant counterparts and acquired specialized and hyperelongated bills. Whereas basal-most penguins like Waimanu and Perudyptes seem to have had comparatively shorter dagger-like bills, resembling the condition observed in loons and large grebes, the acquisition of a hyperelongated bill in penguins seems to be related to the appearance of giant taxa. This highly specialized morphology is unique among seabirds and occupies a morphospace quadrant rarely explored by extant divers, to which the western grebe offers the closest analogue. The similarities between stem penguins and great grebes, along with several other morphological features, are congruent with the hypothesis that at least some giant penguins were specialized in the capture of agile pelagic prey such as fish and/or squid by spear-diving, a strategy rarely seen among living aquatic birds.

Although Oligocene and Miocene crownward taxa retain an elongated spear-like bill (i.e., Platydyptes, Paraptenodytes), modern penguins seem to have acquired a shorter bill 
early in their evolution. Overall, most crown penguins fill a distinct region of cranial morphospace that is largely unexplored by other seabirds, although fossil crown taxa tend to invade the space occupied by Procellariiformes. The analyses also show that the skulls of penguins that incorporate zooplankton as an important item in their diet are significantly different from the skulls of those that do not. Considering the relationships between extant penguins, it seems that the most basal modern penguins could have been unspecialized fish eaters that later originated at least two plankton-eater lineages (Pygoscelis and Eudyptes) and one of specialized fish eaters (Spheniscus) that relies on a powerful bite to catch its prey instead of spear-diving.

\section{Acknowledgments}

I want to thank R. Salas (Museo de Historia Natural de la Universidad Nacional de San Marcos, Peru), D. Pol (Museo Paleontologico Egidio Feruglio, Argentina), and P. Jadwiszczak (Uniwersytet w Białymstoku, Poland) for facilitating the access to the fossil specimens under study. Two anonymous reviewers helped to improve the article. Special thanks are given to the Palaeontological Association, the Division of Ornithology Collection Study Grant of the $\mathrm{AMNH}$, and the University of Bristol Alumni Foundation Postgraduate travel grant, which provided financial support for my visits to collections; and the Becas Chile grant, which funded my Ph.D. studies, during which I developed this research. Finally I want to thank M. Benton (University of Bristol, UK) for his support.

\section{Literature Cited}

Acosta Hospitaleche, C. 2011. A new Patagonian penguin skull: taxonomic value of cranial characters. Ameghiniana 48:605-620. Acosta Hospitaleche, C., C. Tambussi, M. Donato, and M. Cozzuol. 2007. A new Miocene penguin from Patagonia and its phylogenetic relationships. Acta Paleontologica Polonica 52:299-314.

Acosta Hospitaleche, C., C. Tambussi, L. Castro, and R. Scasso. 2008. Palaeospheniscus patagonicus (Aves, Spheniscidae): new discoveries from the Early Miocene of Argentina and its paleoenvironmental significance. Journal of Paleontology 82:565-575.

Ashmole, N. P. 1971. Sea bird ecology and the marine environment. Pp. 223-286 in D. S. Farner, and J. R. King, eds. Avian biology, Vol. 1. Academic Press, London.

Bird Skull Collection. 2000-2017. skullsite.com, accessed 2013-2015. Bookstein, F. L. 1991. Morphometric tools for landmark data. Cambridge University Press, Cambridge.
Borboroglu, P. G., and P. D. Boersma. 2013. Penguins, natural history and conservation. University of Washington Press, Seattle.

Bühler, P., L. D. Martin, and L. M. Witmer. 1988. Cranial kinesis in the Late Cretaceous birds Hesperornis and Parahesperornis. Auk 105:111-122.

Clarke, J., D. Ksepka, M. Stucchi, M. Urbina, N. Giannini, S. Bertelli, Y. Naváez, and C. A. Boyd. 2007. Paleogene equatorial penguins challenge the proposed relationship between biogeography, diversity, and Cenozoic climate change. Proceedings of the National Academy of Sciences USA 104:11545-11550.

Clarke, J. A., D. T. Ksepka, R. Salas Gismondi, A. J. Altamirano, M. D. Shawkey, L. D'Alba, J. Vinther, T. J. DeVries, and P. Baby. 2010. Fossil evidence for evolution of the shape and color of penguin feathers. Science 330:954-957.

Croxall, J. P., and R. W. Davis. 1999. Penguins: paradoxes and patterns. Marine Ornithology 27:1-12.

Davis, L. S., and M. Renner. 2003. Penguins. Yale University Press, New Haven, Conn.

Degrange, F., D. Ksepka, and C. Tambussi. 2018. Redescription of the oldest crown clade penguin: cranial osteology, jaw myology, neuroanatomy, and phylogenetic affinities of Madrynornis mirandus. Journal of Vertebrate Paleontology 38:e1445636.

del Hoyo, J., A. Elliott, J. Sargatal, D. A. Christie, and E. de Juana, eds. 2015. Handbook of the birds of the world alive. Lynx Edicions, Barcelona. http://www.hbw.com.

Digital Morphology. 2002-2019. digimorph.org, accessed 20132015.

Duijm, M. J. 1951. On the head posture in birds and its relation to some anatomical features. I-II. Proceedings of the Koninklijke Nederlandse Akademie van Wetenschappen, Series C, Biological and Medical Sciences 54:202-271.

Foth, C., and O. W. M. Rauhut. 2013. Macroevolutionary and morphofunctional patterns in theropod skulls: a morphometric approach. Acta Palaeontologica Polonica 58:1-16.

Haidr, N., and C. Acosta Hospitaleche. 2012. Feeding habits of Antarctic Eocene penguins from a morpho-functional perspective. Neues Jahrbuch für Geologie und Paläontologie 263:125-131.

Haidr, N., and C. Acosta Hospitaleche. 2014. Miocene Patagonian penguins: craniomandibular morphology and functional mechanics. Alcheringa 38:273-280.

Hallgrimsson, B., C. J. Percival, R. Green, N. M. Young, W. Mio, and R. Marcucio. 2015. Morphometrics, 3D imaging, and craniofacial development. Current Topics in Developmental Biology 115: 561-597.

Hammer, Ø., D. A. T. Harper, and P. D. Ryan. 2001. PAST: Paleontological statistics software package for education and data analysis. Palaeontologia Electronica 4(1):ar4.

Harrison, C. J. O., and C. A. Walker. 1976. A reappraisal of Prophaethon shrubsolei Andrews (Aves). Bulletin of the British Museum of Natural History (Geology) 27:1-30.

Hofer, H. 1952. Der Gestaltwandel des Schadels der Saugetiere und Vogel, mit besonderer Berucksichtigung der Knickungstypen und der Schadelbasis. Verhandlungen der Anatomischen Gesellschaft 50:102-113.

Jadwiszczak, P. 2006. Eocene penguins of Seymour Island, Antarctica: the earliest record, taxonomic problems and some evolutionary considerations. Polish Polar Research 27:287-302.

Jarvis et al. 2014. Whole-genome analyses resolve early branches in the tree of life of modern birds. Science 346:1320-1331.

Kennedy, M., and R. D. M. Page. 2002. Seabird supertrees: combining partial estimates of Procellariiform phylogeny. Auk 119:88-108.

Kennedy, M., and H. G. Spencer. 2014. Classification of the cormorants of the world. Molecular Phylogenetics and Evolution 79:249-257.

Kennedy, M., S. A. Taylor, P. Nádvorník, and H. G. Spencer. 2013. The phylogenetic relationships of the extant pelicans inferred 
from DNA sequence data. Molecular Phylogenetics and Evolution 66:215-222.

Klingenberg, C. P. 2011. MorphoJ: an integrated software package for geometric morphometrics. Molecular Ecology Resources 11:353-357.

Ksepka, D. T., and T. Ando. 2011. Penguins past, present, and future: trends in the evolution of the Sphenisciformes. Pp. 155-186 in G. Dyke, and G. Kaiser, eds. Living dinosaurs, the evolutionary history of modern birds. Wiley-Blackwell, Hoboken, N.J.

Ksepka, D. T., and S. Bertelli. 2006. Fossil penguin (Aves: Sphenisciformes) cranial material from the Eocene of Seymour Island (Antarctica). Historical Biology 18:389-395.

Ksepka, D. T., and J. A. Clarke. 2010. The basal penguin (Aves: Sphenisciformes) Perudyptes devriesi and a phylogenetic evaluation of the penguin fossil record. Bulletin of the American Museum of Natural History 337:1-77.

Ksepka, D. T., J. A. Clarke, T. J. DeVries, and M. Urbina. 2008. Osteology of Icadyptes salasi, a giant penguin from the Eocene of Peru. Journal of Anatomy 213:131-147.

Ksepka, D. T., R. E. Fordyce, T. Ando, and C. M. Jones. 2012. New fossil penguins (Aves: Sphenisciformes) from the Oligocene of New Zealand reveal the skeletal plan of stem penguins. Journal of Vertebrate Paleontology 32:235-254.

Ksepka, D. T., A. Balanoff, M. A. Bell, and M. D. Houseman. 2013. Fossil grebes from the Truckee Formation (Miocene) of Nevada and a new phylogenetic analysis of Podicipediformes (Aves). Palaeontology 56:1149-1169.

LaPorte, N., R. W. Storer, and G. L. Nuechterlein. 2013. Western grebe (Aechmophorus occidentalis), Version 2.0. In A. F. Poole, ed. The birds of North America. Cornell Lab of Ornithology, Ithaca, NY. https://doi.org/10.2173/bna.26a.

Lawrence, G. E. 1950. The diving and feeding activity of the Western Grebe on the breeding grounds. Condor 52:3-16.

Marples, B. J. 1952. Early Tertiary penguins of New Zealand. New Zealand Geological Survey Paleontological Bulletin 20:1-66.

Marugán-Lobón, J., and A. D. Buscalioni. 2003. Disparity and geometry of the skull in Archosauria. Biological Journal of Linnean Society 80:67-88.

Marugán-Lobón, J., and A. D. Buscalioni. 2004. Geometric morphometrics in macroevolution: morphological diversity of skull in modern avian forms in contrast to some theropod dinosaurs. Pp. 157-173 in A. M. T. Elewa, ed. Morphometrics: applications in biology and paleontology. Springer, Berlin.

Marugán-Lobón, J., and A. D. Buscalioni. 2006. Avian skull morphological evolution: exploring exo- and endocranial covariation with two-block partial least squares. Zoology (Jena) 109:217-30

Myrcha, A., Tatur, A., and R. Delvalle. 1990. A new species of fossil penguin from Seymour Island, West Antarctica. Alcheringa 14:195-205.

Nelson, N. 1980. Seabirds, their biology and ecology. Hamlyn Publishing Group, London.

Olson, S. L. 1977. A Lower Eocene frigatebird from the Green River Formation of Wyoming (Pelecaniformes, Fregatidae). Smithsonian Contributions to Paleobiology 35:1-33.
Olson, S. L. 1985. The fossil record of birds. Pp. 79-252 in D. S. Farner, J. R. King, and K. C. Parkes, eds. Avian biology, Vol. 8. Academic Press, London.

Patterson, S. A., J. A. Morris-Pocock, and V. L. Friesen. 2011. A multilocus phylogeny of the Sulidae (Aves: Pelecaniformes). Molecular Phylogenetics and Evolution 58:181-191.

Ponganis, P. J., R. P. Van Dam, G. Marshall, T. Knower, and D. H. Levenson. 2000. Sub-ice foraging behaviour of emperor penguins. Journal of Experimental Biology 203:3275-3278.

Rohlf, F. J. 2003. TpsRelw, relative warps analysis, Version 1.36. Department of Ecology and Evolution, State University of New York, Stony Brook.

Rohlf, F. J. 2005. TpsDig, digitize landmarks and outlines, Version 2.05. Department of Ecology and Evolution, State University of New York, Stony Brook.

Seabird Osteology. 2002-2013. shearwater.nl, accessed 2013-2015.

Siegel, A. F., and R. H. Benson. 1982. A robust comparison of biological shapes. Biometrics 38:341-350.

Slack, K. E., C. M. Jones, T. Ando, G. L. Harrison, R. E. Fordyce, U. Arnason, and D. Penny. 2006. Early penguin fossils, plus mitochondrial genomes, calibrate avian evolution. Molecular Biology and Evolution 23:1144-1155.

Smith, N. A. 2011. Taxonomic revision and phylogenetic analysis of the flightless Mancallinae (Aves, Pan-Alcidae). ZooKeys 91:1-116.

Smith, N. A., and J. A. Clarke. 2015. Systematics and evolution of the Pan-Alcidae (Aves, Charadriiformes). Journal of Avian Biology 46:125-140.

Smith, N. D. 2010. Phylogenetic analysis of Pelecaniformes (Aves) based on osteological data: implications for waterbird phylogeny and fossil calibration studies. PLoS ONE 5(10):e13354.

Sprengelmeyer, Q. D. 2014. A phylogenetic reevaluation of the genus Gavia (Aves: Gaviiformes) using next-generation sequencing. Master's thesis, Paper 1. Northern.

Stucchi, M. 2002. Una nueva especie de Spheniscus (Aves, Spheniscidae) de la formación Pisco, Perú. Boletín de la Sociedad Geológica del Perú 94:17-24.

Stucchi, M., M. Urbina, and A. Giraldo. 2003. Una nueva especie de Spheniscidae del Mioceno tardío de formación Pisco, Perú. Bulletin de l'Institut Français d'Etudes Andines 32:361-375.

Tambussi, C., and C. Acosta Hospitaleche. 2008. Skull shape analysis and diet of South American fossil penguins (Sphenisciformes). Oryctos 7:137-145.

Tatsuta, T., K. H. Takahashi, and Y. Sakamaki. 2018. Geometric morphometrics in entomology: basics and applications. Entomological Science 21:164-184.

Virtual Zooarchaeology of the Arctic Project. 2010-2019. bones.iri.isu.edu, accessed 2013-2015.

Wijnker, E., and S. L. Olson. 2009. A revision of the fossil genus Miocepphus and other Miocene Alcidae (Aves: Charadriiformes) of the western North Atlantic Ocean. Journal of Systematic Palaeontology 7:471-487.

Zusi, R. L. 1975. An interpretation of skull structure in penguins. Pp. 55-84 in B. Stonehouse, ed. The biology of penguins. Macmillan, London. 